\title{
La inclusión de las PyMEs en la Cadena de valor de la Industria Automotriz en México en el marco del Tratado Trans-Pacífico (TтP)
}

The inclusion of SMEs in the Value Chain of the Automotive Industry in Mexico under the Trans-Pacific Treaty (TPP)

\section{Selene Jiménez Bautista *}

\section{Carlos Mario Rodríguez Peralta **}

* Profesora de Tiempo Completo, Unidad Académica Profesional Nezahualcóyotl, UAEM.

** Profesor de Asignatura, Facultad de Economía, UNAM.

\section{Palabras clave}

Estudios de industrias, Automóviles,

Comercio por sectores industriales

Key words

Industry Studies, Automobiles, Country and Industry Studies of Trade

JEL

L6, L62, F14

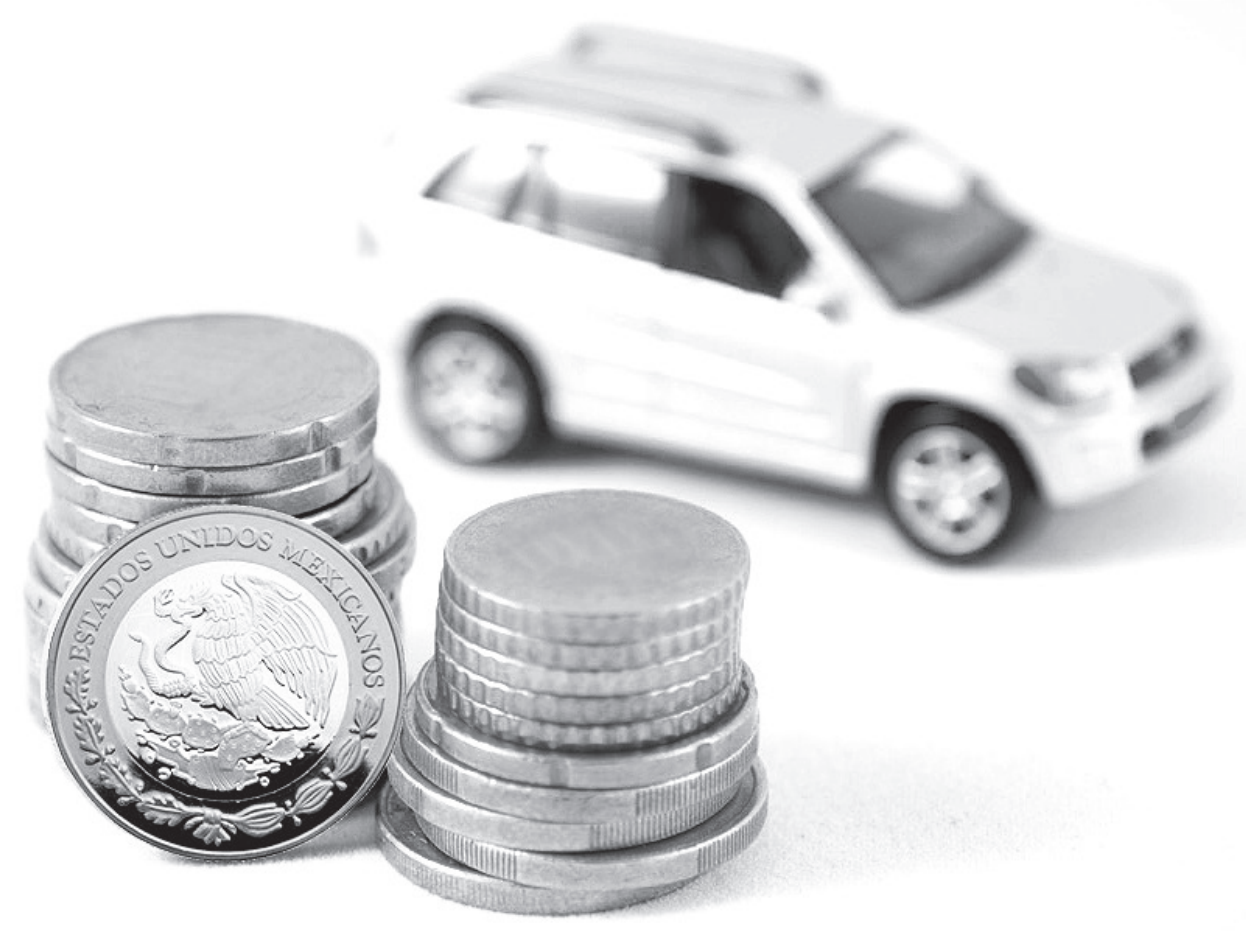




\section{Selene Jiménez Bautista y Carlos Mario Rodríguez Peralta |}

La inclusión de las PyMEs en la Cadena de valor de la

Industria Automotriz en México en el marco del TTP

\section{Resumen}

Considerando la importancia y multiplicidad de acuerdos comerciales que ha firmado México, la relevancia de la Industria Automotriz en el país, así como la importancia de las Pequeñas y Medianas empresas (PYMES) en su contribución al nivel de empleo, se plantea en el presente artículo el estudio de la posibilidad de inclusión de las Pymes en la Industria Automotriz, dentro de un esquema de apertura comercial de última generación (El Acuerdo Transpacífico de Cooperación Económica, Trans-PacificPartnership, TPP).

Por tanto, el presente artículo tiene por objeto el análisis de la problemática de inclusión de las PyMEs en la cadena de valor automotriz, dentro de las oportunidades que los acuerdos comerciales pueden generar.

Tomando como partida el punto de vista de la teoría del oligopolio y el estudio de las redes globales de producción, se plantea el estudio de las características generales de la red global en la Industria Automotriz, a través del análisis de las empresas armadoras y empresas de autopartes de primer, segundo y tercer nivel y la forma en que se toman las decisiones de ingreso a la red. Se considera además que las armadoras y proveedoras de primer nivel son quienes tienen el papel de líderes de la cadena y, en última instancia, toman las decisiones con respecto al ingreso de nuevos jugadores dentro de la red.

Se plantea así, que dadas las características del producto, la red y la forma en la que se llevan a cabo los procesos productivos y la toma de decisiones, resulta inviable y e incluso poco atractivo para las PymEs incluirse en la red global de producción automotriz.

\section{Abstract}

Based on the consideration of the importance and multiplicity of trade agreements signed by Mexico; the importance of the Automotive Industry in the country, as well as the importance of Small and Medium Enterprises (PYMES) in employment at the national level, this paper pretends review the possibility of including SMEs (PYMES) in the automotive global network, within a context of latest generation trade opening agreement (Trans-Pacific Partnership, TPP).

The purpose of this article is to analyze the problem of the inclusion of SMEs (PYMES) in the automotive value chain, within the opportunities that trade agreements can generate.

Thus, starting from the point of view of the theory of oligopoly and the study of the global production networks, this paper review the general characteristics of the automotive global network, through the analysis of the assemblers, and first-tier and second-tier suppliers and the way in which decisions are taken to enter to the global network. It is also considered that assemblers and first-tier suppliers are both the leaders and, ultimately, are the decision makers about the entry of new players into network.

Thus, given the characteristics of the product, the network and the way in which production processes and decision-making are carried out, this paper concludes it is unfeasible and even unattractive for SMEs (PYMES) to be included in the automotive global production network.
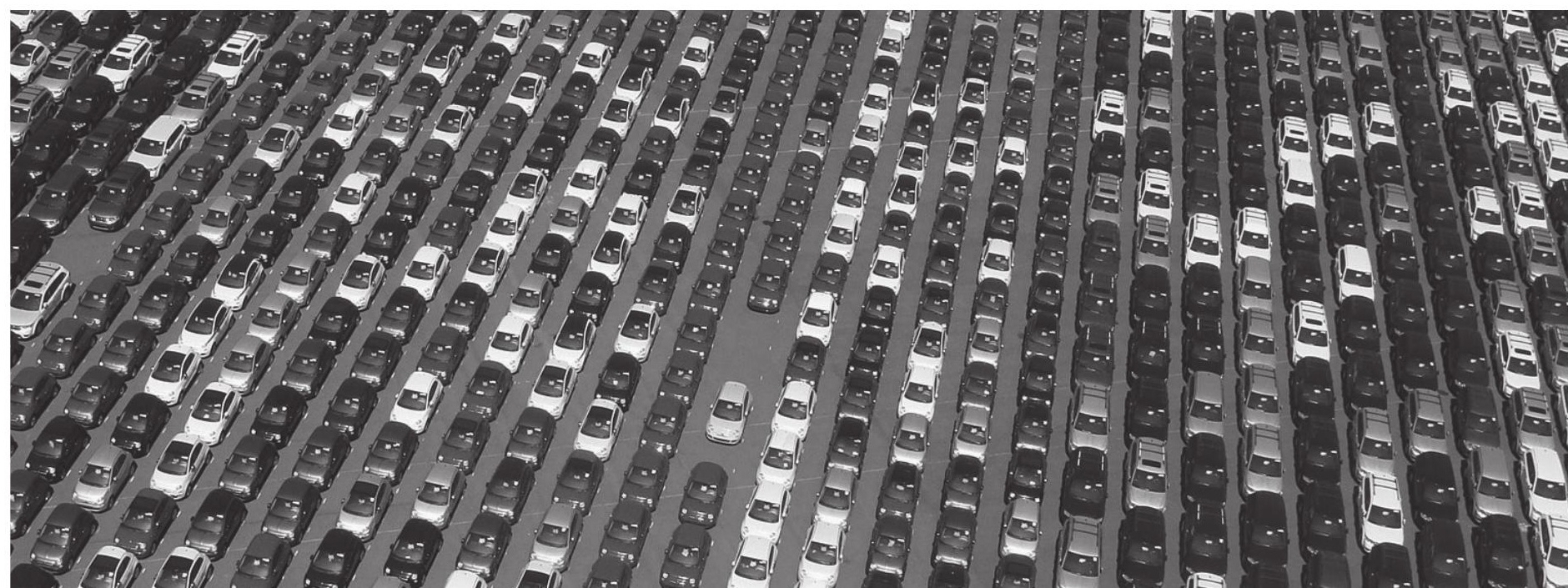


\section{Introducción}

Los acuerdos comerciales que México ha firmado, han traído muchas consecuencias, de entre las que se pueden destacar, los beneficios para las grandes empresas (nacionales o extranjeras). Esto se debe a que con la apertura comercial se ha potenciado la capacidad de la gran empresa para alcanzar nuevos mercados. Sin embargo, mucho se ha criticado el hecho de que las Pymes queden excluidas de los beneficios de dichos acuerdos comerciales, y que incluso se les ha colocado en una aposición de vulnerabilidad al quedar fuera de la competencia frente a las gigantes beneficiadas, por lo que se ha sugerido la generación de una política capaz de potenciar sus capacidades debido a su notable importancia e impacto sobre la economía del país, y darles la oportunidad de incluirse en los grandes procesos desatados por la apertura comercial.
Adicionalmente se puede hacer mención de una de las industrias que se ha visto sumergida en una dinámica sin precedentes con el proceso de apertura comercial en México: la industria automotriz. Cabe destacar que dicha industria ha sido de notable importancia en las economías nacionales del mundo por su papel como fuerza de arrastre para el desarrollo de otros sectores debido a su alta necesidad de proveedores de otras industrias. Para el país, la industria automotriz ha representado históricamente un sector clave para su desarrollo. Su participación en las exportaciones la coloca como la industria más importante, por encima incluso de la petrolera.

En el 2011, 4 de cada 5 vehículos producidos en México se exportaron (Secretaría de Economía, 2012), lo que posicionó a nuestro país entre los más importantes productores a nivel mundial. Así, la producción automotriz en México, medida por el total de vehículos

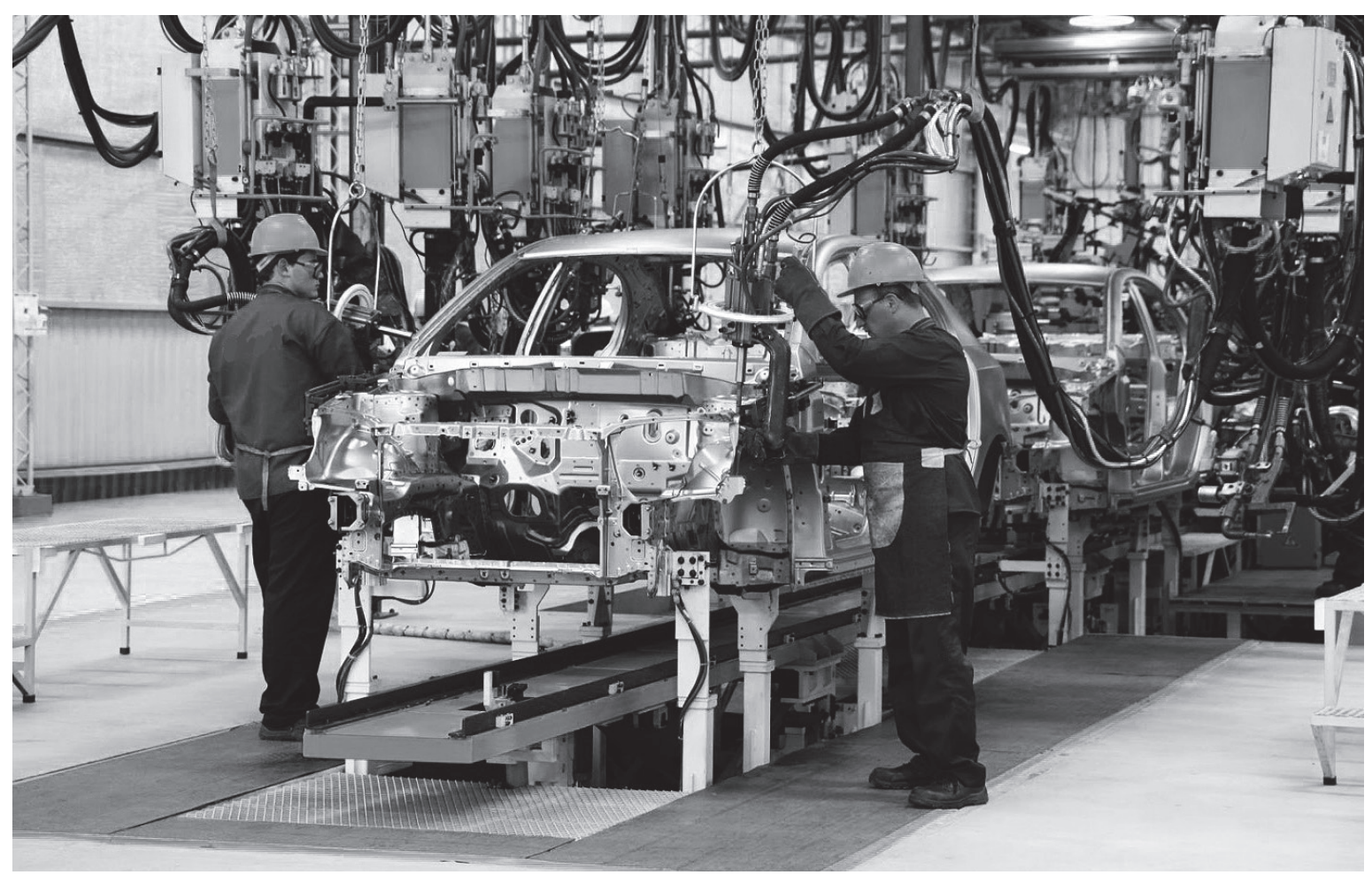


producidos, ha avanzado de la posición número 10 en el 2009, a la posición número 9 en el 2010, a la número 8 en los años 2011 a 2013, y para el 2014 y 2015 ascendiendo al lugar número 7 , colocándose tan sólo por debajo de China, Estados Unidos, Japón, Alemania, Corea del Sur e India, (datos de la Organisation Internationale des Constructeurs d' Automobiles, OICA).

En el 2011, la industria automotriz generó el $16 \%$ de la ocupación de total de la industria manufacturera, aportando el $21.63 \%$ del valor de la producción del total de la misma (Datos del INEGI, BIE).

Tomando en consideración lo anterior, se plantea el estudio de la posibilidad de inclusión de las pymes en la Industria Automotriz, en el marco de la posible generación de política y su pertinencia, dentro de un esquema de apertura comercial de última generación (El Acuerdo Transpacífico de Cooperación Económica, Trans-Pacific Partnership, TPP).

El presente artículo entonces, tiene por objeto el análisis de la problemática de inclusión de las Pymes en la cadena de valor automotriz, dentro de las oportunidades que los acuerdos comerciales pueden generar, dado que han funcionado como catalizadores para el incremento en la dinámica de la industria. Así pues, partiendo desde el punto de vista de la teoría del oligopolio y el estudio de las redes globales de producción, se plantea el estudio de las características generales de la red global Automotriz a través del análisis de las empresas armadoras, y empresas de autopartes de primer, segundo y tercer nivel. Se considera además que son las armadoras y proveedoras de primer nivel quienes tienen el papel de líderes de la cadena y, en última instancia, toman las decisiones con respecto al ingreso de nuevos jugadores dentro de la red.
Se plantea así, que dadas las características del producto, la red y la forma en la que se llevan a cabo los procesos productivos, resulta inviable e incluso poco atractivo para las PYMEs incluirse en la red global de producción automotriz.

\section{La empresa y su forma de organización}

La empresa puede ser definida como un conjunto de recursos productivos, materiales y humanos, que se organizan de una manera tal que le permita conseguir un objetivo. Para algunos autores, como Eichner (1988) y Penrose (1956), el objetivo de la empresa moderna es expandirse a la más alta tasa posible. Para conseguir tal fin, la empresa es capaz de organizar sus recursos para producir, ya sea bienes y/o servicios.

Aquél mundo en donde la empresa competía en condiciones iguales a las de sus rivales poco a poco fue desapareciendo con el devenir de los años, si es que alguna vez existió una forma parecida (Sylos, 1966). Así pues, subsisten hoy en día las empresas pequeñas y medianas, que conviven con empresas grandes que tienen la capacidad de fijar precios. Si las empresas de menor tamańo existen, es porque a las empresas mayores les conviene que existan. Ya sea porque son capaces de abastecer distintos nichos de mercado que a las grandes no les es provechoso, en términos de costos y ganancias, o bien porque cubren una cuota de producción tal, sumada a la de las grandes empresas, que permite mantener un precio de equilibrio que impida a otras grandes empresas entrar, dado que al hacerlo tendrían que reducir su margen de ganancia, lo que eliminaría el incentivo de entrada (Sylos, 1966).

La empresa moderna, independientemente de su tamańo, puede verse como la unidad 


\section{n el 2011, 4 de cada 5 vehículos producidos en México se exporta- ron, lo que posicionó a} nuestro país entre los más im-

\section{portantes productores a nivel}

\section{mundial}

básica de la economía, ya que es un importante centro en donde se toman decisiones clave. Dentro del conjunto de decisiones relevantes que la empresa debe tomar se incluyen no solo cuánto producir o cuál precio determinar (principalmente para el caso de las empresas mayores) sino además cuánto invertir y cómo financiar tal inversión (Eichner, 1988).

Hoy en día la economía "consiste predominantemente de industrias oligopólicas en estructura, con la resultante habilidad de mantener sobre el tiempo cierto margen, o mark up, sobre los costos" (Eichner, 1988, pp. 29).

Dado que las pequeñas y medianas empresas son seguidoras, y se subordinan a las decisiones de las grandes empresas, también llamadas megacorporaciones (Eichner, 1988) o multinacionales (Penrose, 1956), el funcionamiento de éstas es la más relevante. Debe considerarse además en un contexto oligopólico, que toda acción de las grandes empresas no puede ser entendida si es aislada de las acciones de otras grandes empresas.

El crecimiento resulta ser de suma importancia para la gran empresa, ya que si no se crece, por lo menos al ritmo de la competencia, correrá el riesgo de ser absorbida o eliminada. Para crecer, la megacorporación hace uso de sus recursos, tratando de combinarlos de la mejor manera posible para hacerse de ventajas, y buscando aprovechar lo que esté a su alcance. Hoy en día, la megacorporación (Eichner, 1988), ha organizado el proceso productivo de manera tal, que le permita conseguir esas ventajas sobre sus competidoras que a su vez le permitan mantener su crecimiento acelerado. El proceso productivo pudo ser divido en eslabones que permiten la especialización y la obtención de economías de escala, a la vez que le permite adaptarse a los cambios de la demanda. Pero éste es un proceso complejo que entrańa la transformación de la industria y de la forma de organización de la gran empresa (o megacorporación), que se pretende describir un poco más adelante.

\section{La Formación de Redes globales de producción}

El mundo económico se encuentra en constante cambio, originado por la constante evolución de los agentes que lo conforman. A finales de los ańos 70 y principios de la década de los 80 , ocurre un proceso de transformación mundial debido a la gran crisis del capitalismo y a la producción Fordista (Rodríguez, 2013), la cual generó, en su tiempo, un proceso de transformación en la empresa y su medio, llevando a una fase de acoplamiento que permitió el esplendor del sistema. Sin embargo, las fuerzas productivas llegaron a su agotamiento, generando problemas graves y la necesidad urgente de un cambio. El nuevo paradigma tencno-económico ${ }^{1}$ surgió con la crisis del anterior (Pérez, 2004), pero éste requería el aco-

1 Concepto que hace referencia a las prácticas óptimas en la producción surgidas de innovaciones radicales, caracterizado por un conjunto de industrias impulsoras con un grupo de tecnologías genéricas aplicables a todas las ramas de las diferentes industrias capaces de dar un nuevo impulso a la dinámica económica (Pérez, 2004). 


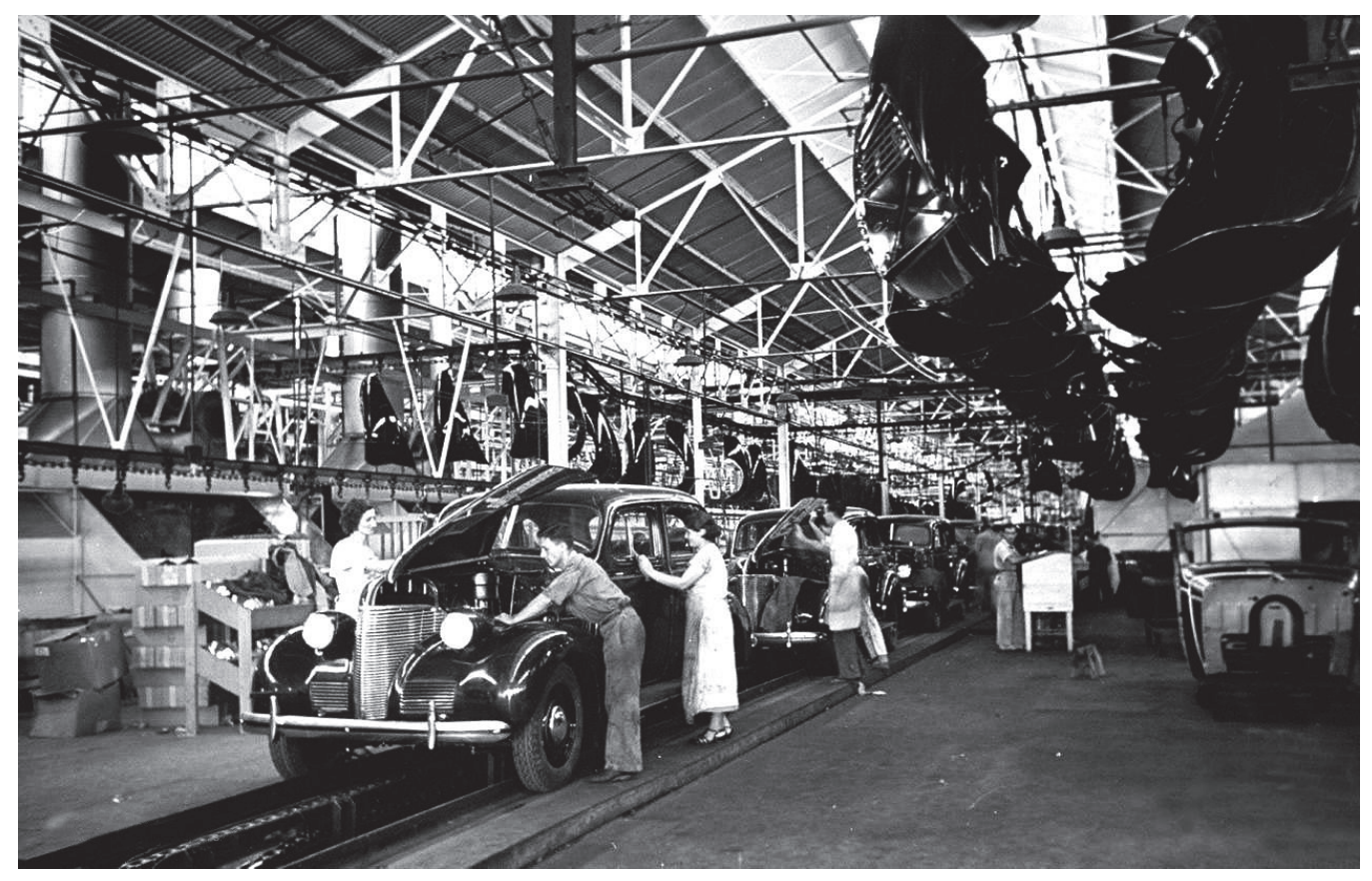

plamiento del entorno para mostrar su máximo potencial, un entorno que se encontraba adaptado a las formas del paradigma en agotamiento que había a su vez sido forjado por la transformación de la empresa en ese entonces. Cabe mencionar que la transformación de la empresa del paradigma en agotamiento, se había originado en el seno de la industria automotriz, al igual que la transformación que habría de dar paso al surgimiento del nuevo paradigma (Fordismo y Toyotismo).

Surge entonces el proceso de descenso de la forma fordista de producción y al mismo tiempo el ascenso de la llamada producción flexible, o Toyotismo, apoyado éste a su vez por la revolución de las Tecnologías de la Información y las Comunicaciones (TICS). Dicha revolución, jugó un papel central en la gran transformación, y confluyó precisamente con el ascenso de la nueva organización productiva (Toyotismo), la cual tuvo sus orígenes en Japón. Dicha revolución apoyó de manera sustancial el paso a la automatización flexible de los procesos productivos, la introducción de la computadora y las redes de computadoras (Dabat, 2002 en Basave, Dabat, Morera, Rivera y Rodríguez, 2002), que a su vez habrían de conformar el nuevo paradigma productivo. Sin duda la nueva forma productiva no habría podido surgir sin la base brindada por la revolución de las Tics.

Éste nuevo paradigma permitía a la empresa producir grandes volúmenes y a la vez generar una producción diferenciada, adaptarse eficazmente a los cambios de la demanda y el desarrollo tecnológico a través de la desintegración productiva. Se logró dar paso así a la automatización flexible y reprogramable, además de la gestión computarizada y la nueva organización del trabajo a partir de los círculos de autocontrol de calidad, la aceleración del flujo continuo de información y materiales entre las secuencias del ciclo del producto, así como la posibilidad de sustituir las grandes series estandarizadas por pequeñas series reprogramables con menores requerimientos de economías de escala (Dabat, 2002) y mayores posibilidades de descentralización, haciéndose 
posible así el fraccionamiento de los procesos productivos que posibilitaba la relocalización parcial de parte de los mismos. Esto último se habría de expresar en una nueva división internacional del trabajo que habría de ligarse a la aglomeración, es decir, a la concentración de las actividades productivas en ciertas ciudades urbano-regionales.

La gran empresa pudo reestructurar sus estrategias para alcanzar sus objetivos. Esta vez lo haría a través de la desintegración productiva y la partición de la cadena de valor, lo que le permitiría deshacerse de aquellas actividades que le fueran menos rentables, y especializarse en aquellas en donde encontrara el mayor potencial, aquella que le permitiera la generación de rentas (Kaplinsky, 2005). Dicho proceso habría de dar origen a lo que Ernst (2003) llama Redes de Producción Globales (RPG). Así, las grandes empresas dentro del sistema oligopólico del fordismo, se perfilaron como las líderes, quienes habrían de romper la cadena de valor en una variedad de funciones discretas y las situarían en donde quiera que se pudiesen llevar a cabo más eficazmente, donde mejorasen el acceso de la empresa a recursos y capacidades, y donde fueran necesitadas para facilitar la penetración de mercados de crecimiento importantes (Ernst, 2003).

El principal propósito de estas redes se convirtió en el de proveer a las líderes de acceso rápido y de bajo costo a los recursos, capacidades y conocimiento que son complementarios a sus capacidades centrales. Las RPG habrían de permitir a las líderes sostener posiciones cuasimonopólicas, generar poder de mercado a través de la especialización y levantar barreras a la entrada (Ernst, 2003).

Bajo éstas características, la aglomeración pudo ser vista como fuente de ventaja para las líderes. Así, retomando la idea Marshalliana de Economías externas e internas, pero des- de el punto de vista de la red global expresado por Kaplinsky (2005), la empresa era capaz de apropiarse de rentas endógenas y exógenas.

En opinión de Kaplinsky (2005), la capacidad de una firma de apropiarse de rentas, le permite colocarse como líder en la red global, determinando quién entra o sale de ella. Así, las empresas generan procesos mediante los cuales aseguran rentas que les garantizan su estancia en la cadena, e incluso les permiten tomar su liderazgo.

\section{La industria Automotriz y la generación de RPG}

Con la caída del Fordismo y el ascenso del Toyotismo, (alrededor de principios de los años 80) las estrategias de reestructuración de las empresas armadoras en los países occidentales estuvieron basadas en la formación de complejos esquemas de cooperación (GM-Toyota, Ford-Mazda, Chrysler-Mitsubishi, Ford-vw como ejemplos) que rebasaban la lógica de la rivalidad productiva. Se trataban de asociaciones Joint Venture para ciertos modelos y/o ciertas plantas, proyectos comunes para el desarrollo de plataformas, cooperación tecnológica-productiva-financiera, dispersión de la propiedad de las firmas por vía de cuotas de

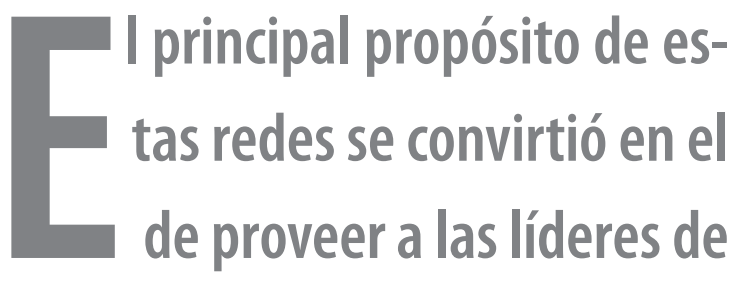

acceso rápido y de bajo costo a los recursos, capacidades y conocimiento que son complementarios a sus capacidades centrales 
acciones, entre otras (Juárez, Lara y Bueno; 2005), volviéndose incluso, difusa la propiedad nacional.

Con la crisis fordista, el número de competidores globales de la industria se redujo de 30 en 1980 a 13 en 2000 (CEPAL, 2010). En este proceso, tomaron gran relevancia las fusiones $\mathrm{y}$ adquisiciones, lo que las coloca como una estrategia para hacer frente al cambio.

Dentro del nuevo esquema productivo, la eliminación de las actividades que se identifican como no propias de las plantas ensambladoras fue de crucial importancia, empezándose desde los años 80 a transferir al outsourcing ${ }^{2}$ los servicios.

La industria de autopartes aquí empezó a jugar un papel muy importante en la nueva configuración de la producción mundial, como parte de la estrategia de las grandes empresas.

Podemos mencionar que a partir de entonces se inició una nueva etapa en la industria de autopartes. En un primer momento (en el modelo Fordista) fue una industria integrada y al mismo tiempo relegada a la condición de apéndice de la industria terminal dedicando su producción a la refacción del parque automotor en circulación. Después, en el periodo de reestructuración posterior a la crisis de 19791982, este segmento tomó relevancia como parte de la estrategia de adopción del nuevo paradigma en el cual la producción se habría de estructurar en una red global. Así, las autopartes tomaron parte de la cadena productiva en segmentos de mayor valor agregado, obligándose a innovar en el desarrollo de procesos y de producto, pero esto a su vez estuvo acom-

2 Subcontratación, proceso mediante el cual se contrata a otras empresas,diferentes de la propia armadora, para que se hagan cargo de parte del proceso productivo. pañado de la reducción del número de proveedores y se observó una reorganización en torno a las plantas ensambladoras.

Algunas de las grandes compañías de autopartes se separaron de sus matrices dedicadas al proceso terminal (Delphi de GM y Visteon de Ford como ejemplos) como forma de acoplamiento a este nuevo esquema de desintegración productiva.

Se desató además un proceso de selección de empresas proveedoras, en donde se incluirían aquellas que proporcionaran excelente calidad y precio en sus productos, además de que pudieran cumplir con estándares específicos que las empresas ensambladoras requerían para seguir su estrategia global de competencia. Las empresas de autopartes de los países desarrollados pronto tomaron ventaja, pues fueron demostrando sus capacidades tecnológicas y de adaptación a la nueva forma de competencia. Para el 2002, de las 30 principales empresas de autopartes (medida por su nivel de ingresos), 12 eran estadounidenses, 11 europeas (de las cuales 5 son alemanas), 6 japonesas y 1 canadiense (Supplement to automotive news, Top Suppliers 2013).

Se establecieron pronto relaciones entre las ensambladoras y autopartistas difíciles de disolver. Las nuevas inversiones se llevarían a cabo pensándose en conjunto, pues a donde iría la ensambladora, la habrían de seguir las autopartistas asociadas, pues se trataba ahora de competir en cadena, una cadena de producción enfrentada a otra.

La fortaleza de las empresas de autopartes, a partir de los años 90, estuvo fundada en su capacidad para generar activos intangibles y especialidades en torno a diseño y fabricación no de un solo producto, sino de familias de productos. Éste proceso ha sido determinante para explicar las cada vez mayores intervenciones de las empresas proveedoras en la fabrica- 
ción del auto y por ende, sentar las bases de la modularización de la producción, cuyo origen data de 1992 y que en la primera mitad de la década de los 90 logra consolidarse. (Juárez, Lara y Bueno; 2005).

Unida a esta estrecha relación entre ensambladora y autopartista, otra estrategia seguida fue el establecimiento de las nuevas plantas de producción. En el período 1996-2000, la mayor parte de las nuevas plantas de las empresas ensambladoras fueron construidas en países en desarrollo, como Brasil, Rusia, China, India, México, Polonia, y a algunos países del sudeste asiático, donde se ofrecían ventajas aprovechables en el nuevo esquema de desintegración productiva como bajos costos laborales y para el consumo de algunas materias auxiliares (electricidad, agua, gas), estímulos fiscales, etc. Así, en su intento de defender sus mercados, la rentabilidad de sus productos y potenciar sus capacidades, los armadoras comenzaron a desplazar su producción hacia sus vecinos: Estados Unidos lo hizo hacia Canadá y México, mientras que en Europa hacia los nuevos miembros de la Unión Europea (Polonia, la República Checa y Eslovaquia) (orcA, 2005).
Así, mediante los cambios producidos, la producción de vehículos se concentró pronto en tres grandes regiones: América del Norte, Asia-Oceanía, y Europa. Dentro de las regiones, el comercio de los productos automotores importados es importante, por ejemplo, la importación de Estados Unidos, Canadá y México tuvieron su origen mayoritario en el propio TLCAN y llegaron al $42 \%$, el $77 \%$ y el $60 \%$, respectivamente, mientras que en el caso de la Unión Europea, el 85\% de sus importaciones provinieron de la misma región (CEPAL, 2010).

Ésta nueva configuración provocó que para el año 2000, las tres zonas obtuvieran participaciones en la producción de alrededor del 30\% (América del Norte, 30.36\%; AsiaOceanía 30.81\%; Europa, 30\%) (Estimación con base en los datos de la OICA).

Se pueden identificar los jugadores que armarían la nueva configuración productiva global. Dichos actores fungiendo como un eslabón productivo, en conjunto formarían la cadena global de valor, la cual sería una estructura jerárquica en la cual se encontraría la líder de la cadena en lo más alto, y detrás de ella un conjunto de proveedoras que a su vez tendrían

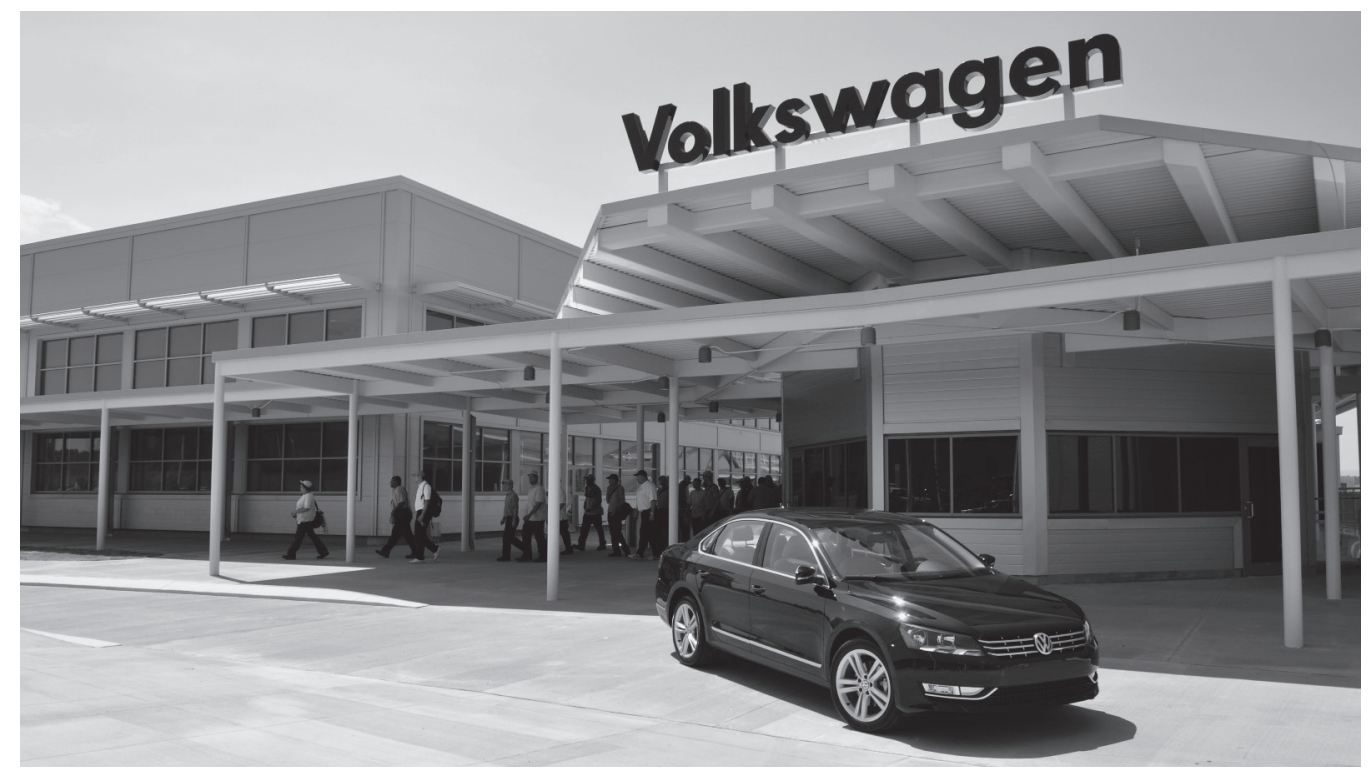


a sus propios proveedores, generando una cadena a modo de red. A los integrantes de ésta cadena en red, se les pueden clasificar de la siguiente manera (Romero, 2011):

- Armadoras (assemblers). Son fabricantes de equipo original (oEM) como Toyota, General Motors (GM), Volkswagen (vw), Ford, Hyundai o Honda, que operan con economías de escala para distribuir los elevados costos de diseño, $\mathrm{I}+\mathrm{D}$ y gestión de marcas. Su ventaja proviene de la capacidad de innovación en nuevos mercados (Romero, 2011). Son los líderes que dirigen la cadena, determinando en gran medida quién se queda y quién asciende en el proceso de producción.

- Proveedores de primer nivel (First-tier supplier): Suministran sistemas complejos e integrados a las armadoras (a una o a varias de ellas). Son capaces de diseñar e integrar componentes, sub ensambles y sistemas y módulos que se envían a la ensambladora y pueden colocarse en el vehículo (Álvarez, 2011). Estas empresas tienen alcance global y ofrecen soluciones creadas específicamente para satisfacer los requerimientos de las armadoras a partir de sus propias capacidades tecnológicas y de innovación. Delphi, Magna y Visteon son ejemplos de estos megaproveedores. Este tipo de proveedor se abastece de otros proveedores, poniéndoles a prueba bajo estrictos niveles de calidad y tiempos de entrega.

- Proveedores de segundo nivel (Second-tier suppliers). Por lo general, son proveedores de componentes y operan con diseños de las armadoras o de los megaproveedores mundiales (proveedores de primer nivel). Requieren habilidades de ingeniería de proceso para reunir condiciones de costo y flexibilidad (Romero, 2011). Pueden producir sistemas para usarse en diferentes plataformas y provee directa o indirectamente a la ensambladora. Comúnmente operan con estándares de calidad ISO 9000 o QS 9000.

- Proveedores de tercer nivel (Third-tier suppliers): Suministran productos básicos y estandarizados, y requieren habilidades rudimen- tarias de ingeniería. Manufacturan componentes para una plataforma o automóvil específico, como son el estampado, fundición de inyección, etc. Compiten eminentemente mediante el precio, las economías de escala y la eficiencia operacional. La madurez de los productos que surten deja poco espacio para la diferenciación.

- Repuestos y componentes (mercado posventa). Es el segmento de la cadena de valor automotriz asociado al mercado de partes y componentes para vehículos. Las empresas compiten predominantemente mediante el precio y las capacidades de ingeniería "inversa" (reverse engineering), las cuales son más importantes que las de innovación, ya que copian los diseños de equipos existentes.

En esta división del trabajo, el incremento en la responsabilidad del proveedor es importante debido a la subcontratación de las partes del automóvil. Las actividades de diseño, en donde las rentas son incrementales, han quedado en las manos de las ensambladoras y de un pequeño número de proveedores de primer nivel. En los últimos años algunas actividades de diseño se han ido moviendo a países en desarrollo porque sus capacidades aumentaron y se necesita disminuir costos (Álvarez, 2011).

Un punto clave en el nuevo esquema productivo es el crecimiento de la importancia de la proveeduría global. Una ensambladora acuerda con sus proveedores de primer nivel el diseño de un nuevo vehículo, el cual será destinado para mercados regionales o globales, por lo cual se requiere que los fabricantes de componentes tengan cada vez más capacidades tecnológicas y de diseño, precios competitivos y calidad. Los proveedores se comprometen a surtir a las ensambladoras y seguirlas a otros países, ubicando sus plantas en las proximidades. Sin embargo, esta preferencia por usar 


\section{as ensambladoras gobiernan la cadena con respecto a los proveedores y establece los estándares de desem- peño con respecto a costo, calidad, tiempo de entrega, emisiones, reciclaje, etcétera}

los mismos proveedores en diferentes partes del mundo limita la posibilidad de desarrollar proveedores locales (Álvarez, 2011).

Las ensambladoras gobiernan la cadena con respecto a los proveedores y establece los estándares de desempeño con respecto a costo, calidad, tiempo de entrega, emisiones, reciclaje, etcétera. Para lograr la competitividad sistémica en la cadena se espera que aquellos que gobiernan promuevan el aprendizaje y escalen capacidades, pero esto depende de dos cosas: en primer lugar, la obligación señalada por el gobierno de los países en los que manufacturan o el interés que tengan las ensambladoras con los proveedores de primer nivel de desarrollar proveedores; en segundo lugar, las capacidades que tengan los proveedores de menor nivel o locales para escalar la producción de componentes (Kaplinsky, 2002 en Álvarez, 2011).

Sin embargo, con la modularización de la producción, es muy difícil el acceso a la cadena. El módulo implica una restricción muy grande para los proveedores locales, por las alianzas que se generan para su producción. La ensambladora y el proveedor de primer nivel en conjunto diseñan los módulos, lo que crea una alianza difícil de disolver. Esto implica que no habrá fácil acceso a la cadena, salvo para productos elementales.

\section{La llegada de grandes inversiones \\ a México ante su apertura comercial (1986)}

Dentro de la gran reconfiguración de la producción mundial de la producción de las grandes armadoras, México jugó un papel fundamental, principalmente para las armadoras estadounidenses, pues en su búsqueda por abatir costos, con ayuda de la desintegración productiva, el país se convertiría en un punto importante de llegada de inversiones a nivel mundial.

Cabe recordar de manera general, que México se había sumergido en una profunda crisis derivada del agotamiento del proceso de Industrialización por Sustitución de Importaciones, por lo que las autoridades en turno decidieron tomar, como principales medidas, abrir al país al comercio exterior y reducir la participación del gobierno en asuntos económicos, medidas que el Consenso de Washington habría de colocar como las apropiadas.

Se puede considerar que la apertura comercial de México, da inicio con la entrada de México al gatt (Acuerdo General sobre Aranceles y Comercio) que oficialmente ocurre el 24 de agosto de 1986. A partir de entonces se profundiza el proceso iniciado un periodo anterior (García, 1993) en el cual se buscaba que 
Selene Jiménez Bautista y Carlos Mario Rodríguez Peralta |

La inclusión de las PyMEs en la Cadena de valor de la

Industria Automotriz en México en el marco del TTP

la producción automotriz en el país se volcara al exterior, debido a constantes problemas que en la balanza de pagos la industria provocaba.

Con la firma de acuerdos internacionales dentro del cual se destaca el Tratado de Libre Comercio de América del Norte (TLCAN), se le permitió a la industria, colocada en el carril del abastecimiento del mercado externo, afianzar su transformación dentro de una red de producción global con características regionales (América del Norte).

La participación del capital extranjero se hace mayoritaria, y la eficiencia de la industria hace del automóvil producido en México un producto de calidad mundial, lo que contrasta fuertemente con las características en los anteriores periodos de la producción de vehículos en el país (García, 1993), Sin embargo, la base de proveeduría nacional que se había generado en los periodos anteriores, se desmantelaría al verse incapaz de satisfacer las necesidades de la nueva industria global.

Así, con el inicio de la apertura comercial y la competencia internacional que entra al país, se aceleró el descenso de la participación de empresas de autopartes pequeñas y medianas, que en su gran mayoría estaban formadas por capitales de origen nacional. Para 1987 la inversión extranjera en la industria de autopartes desplaza de manera definitiva a la inversión nacional y en términos de la inversión global se transforma en el principal componente de las inversiones automotrices (García, 1993).

El impresionante desenvolvimiento que obtuvo la industria automotriz al elevar el valor de su producción y convertirse en una importante industria exportadora (Gráfica 1) tenía sus características. Las grandes plantas

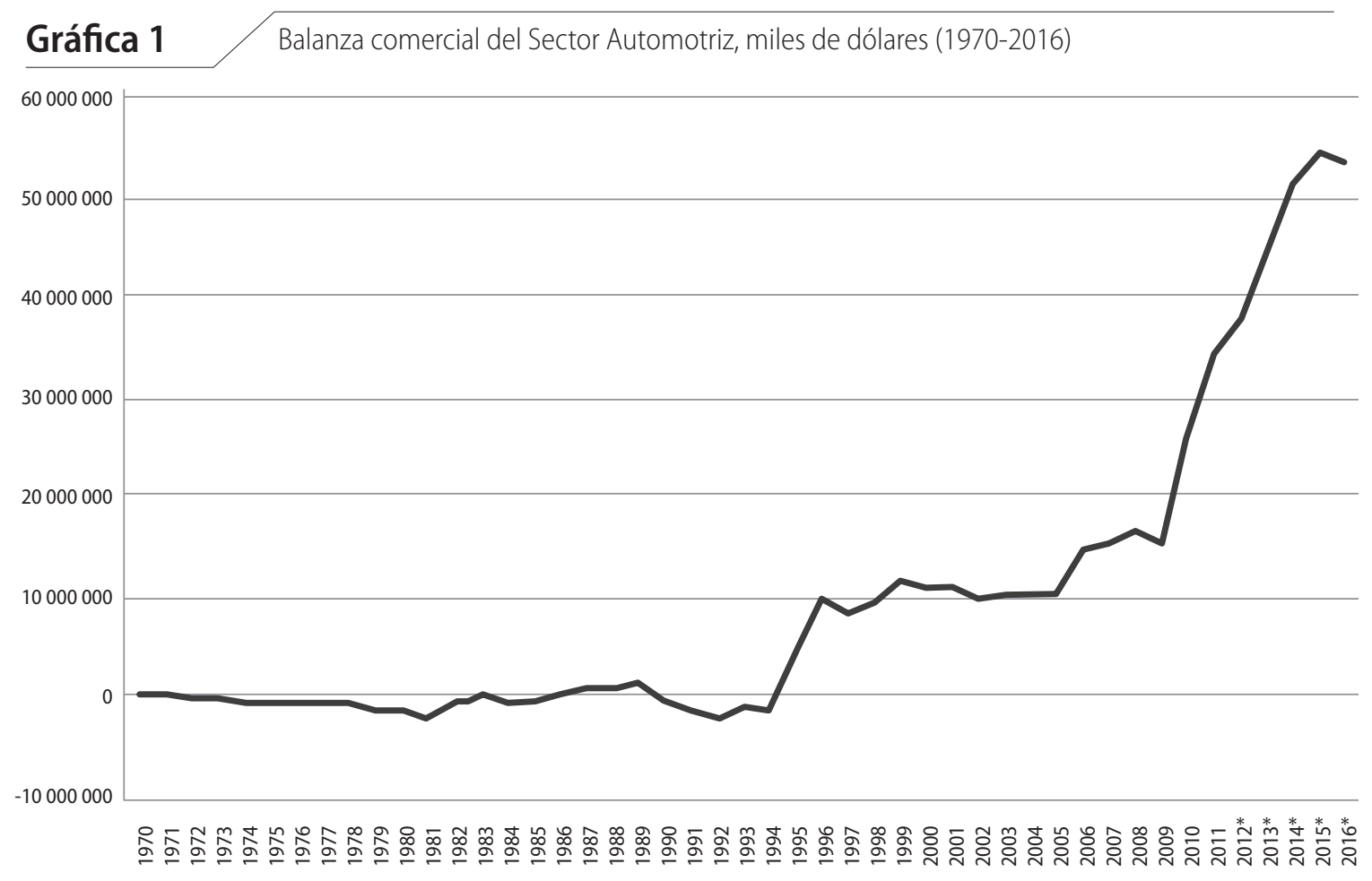

Fuente: elaboración propia con base en datos de BADECEL. CUCI Revisión 1. Incluye las partidas $7321,7322,7323,7324,7325,7326,7327,73281$ y 73289.

*Estimaciones a partir de datos del BIE, INEGI. 
ensambladoras establecidas en el país traían consigo a sus principales proveedoras, quienes a su vez traían consigo a las suyas, relegando a las empresas nacionales la producción de insumos menores.

Con la apertura comercial, el comercio intraindustrial se vio incrementado (López y Rodil, 2008), lo que significó que la gran parte del comercio de la industria se lleva a cabo entre participantes de la misma cadena, lo que permitiría observar que México habría de convertirse en una parte de una gran cadena regional de producción, pues dicho comercio intraindustrial, se lleva acabo con participantes de distintos países. Así, las ensambladoras de origen extranjero, junto con sus proveedoras principales, en su mayoría también de origen extranjero, habrían de producir en México autos competitivos a nivel mundial, utilizando las ventajas del país (como mano de obra relativamente barata, acceso preferencial al mercado de Estados Unidos, incentivos otorgados por el gobierno, entre otros) importando los componentes de mayor contenido tecnológico, con el fin principal de venderlos en el mercado de Estados Unidos.

\section{La problemática de las PYMES \\ y la Industria Automotriz en México}

\section{Identificación del concepto de Pequeñas y Medianas Empresas (PYMES)}

La clasificación de las empresas por su tamaño es una de las diferentes formas de agrupar a las unidades empresariales mediante algún criterio en común, por ejemplo, número de empleados, nivel de ingresos o ventas, etc, con el fin de identificar por grandes agregados, las necesidades, dificultades, fortalezas o debilidades con las que las mismas cuentan.

La clasificación que identifican La Secretaría de Economía (sE) y la Secretaría de Hacienda y Crédito Público (sHCP) en su reclasificación de las Mipymes (2009), es la siguiente:

Cuadro 1

Clasificación micro, pequeñas y medianas empresas

\begin{tabular}{|c|c|c|c|c|}
\hline Tamaño & Sector & $\begin{array}{l}\text { Rango de número de } \\
\text { trabajadores }\end{array}$ & $\begin{array}{l}\text { Rango de monto de } \\
\text { ventas anuales (mdp) }\end{array}$ & Tope máximo combinado* \\
\hline Micro & Todas & Hasta 10 & Hasta $\$ 4$ & 4.6 \\
\hline \multirow{2}{*}{ Pequeña } & Comercio & Desde 11 hasta 30 & $\begin{array}{l}\text { Desde } \$ 4.01 \text { hasta } \\
\$ 100\end{array}$ & 93 \\
\hline & Industria y servicios & Desde 11 hasta 50 & $\begin{array}{l}\text { Desde } \$ 4.01 \text { hasta } \\
\$ 100\end{array}$ & 95 \\
\hline \multirow{3}{*}{ Mediana } & Comercio & Desde 31 hasta 100 & \multirow{2}{*}{$\begin{array}{l}\text { Desde } \$ 100.1 \text { hasta } \\
\$ 250\end{array}$} & \multirow{2}{*}{235} \\
\hline & Servicios & Desde 51 hasta 100 & & \\
\hline & Industria & Desde 51 hasta 250 & $\begin{array}{l}\text { Desde } \$ 100.1 \text { hasta } \\
\$ 250\end{array}$ & 250 \\
\hline
\end{tabular}

*Tope Máximo Combinado = (Trabajadores) X 10\% + (Ventas Anuales) X 90\%

Fuente: Nacional Financiera NAFIN. 
Dentro de la mencionada clasificación se hace énfasis en el número de empleados y el monto de las ventas anuales de las unidades empresariales para ser consideradas como Micro, Pequeńa o Mediana empresas, con el fin ser objeto de alguna política.

En el país, es conocido que las micro, pequeñas y medianas empresas (MIPYMEs) tienen un alto impacto en el producto y empleo nacionales. De acuerdo el Instituto Nacional de Estadística y Geografía, en México existen aproximadamente 4 millones 15 mil unidades empresariales, de las cuales $99.8 \%$ son PYMES que generan 52\% del Producto Interno Bruto (PIB) y $72 \%$ del empleo en el país (Proméxico, 2016).

Algunas de las ventajas y desventajas generales que Proméxico identifica de las pyMEs, como un gran agregado dentro del universo de las unidades empresariales existentes en México son (Proméxico, 2016):

- Se trata de un importante motor de desarrollo del país.

- Tienen capacidad de ampliar o disminuir el tamaño de la planta, así como cambiar los procesos técnicos necesarios.

- Poseen una dinámica tal que les es posible llegar a convertirse en empresas grandes.

- Tienen una gran capacidad de generación de empleos, por lo que absorben una porción importante de la población económicamente activa.

- Relativa facilidad de asimilación y adaptación de nuevas tecnologías.

- Enfrentan el problema de la fuga de personal capacitado y problemas derivados de la falta de organización como: ventas insuficientes, debilidad competitiva, mal servicio, mala atención al público, precios altos, activos fijos excesivos, mala ubicación, descontrol de inventarios, problemas de impuestos y falta de financiamiento adecuado y oportuno.

- Se les dificulta contratar personal especializado y capacitado por la falta de capacidad de pago de salarios competitivos.

- No existe reinversión de utilidades para mejorar el equipo y las técnicas de producción.

- Su producción cuenta con deficiencias en calidad debido a mínimos o inexistentes controles de la misma.

- Falta de capacidad de absorción de gastos de capacitación del personal.

Es de especial interés para el presente artículo los último cuatro puntos entre las características que Proméxico identifica en las PyMEs: Dificultad de contratación de personal especializado, falta de reinversión de utilidades para la mejora del equipo y las técnicas de producción (innovación), producción deficiente en calidad, y bajas capacidades de absorción de gastos de capacitación.

\section{Los requerimientos de la industria automotriz global}

Si bien la industria automotriz ha tenido un fuerte crecimiento desde la apertura comercial (principalmente con entrada en vigor del TLCAN, 1994: Gráfica 1) de tal manera que muchos la identifican como un área de oportunidad, el ingreso a ésta está limitado por los requerimientos de la red de proveeduría impuesta por la líder global, pues es ella quien centraliza el control internacional de las compras y el diseño).

Como se ha mencionado antes, con la reestructuración productiva, que desembocó en la formación de redes globales de producción y la desintegración vertical de la producción, entre otras características, permitieron la existencia de grandes proveedores que participaran activamente en el diseńo y desarrollo del producto.

El proceso de producción se perfeccionó hasta llegar a la incorporación de módulos completos, lo que permitiría una convergencia 


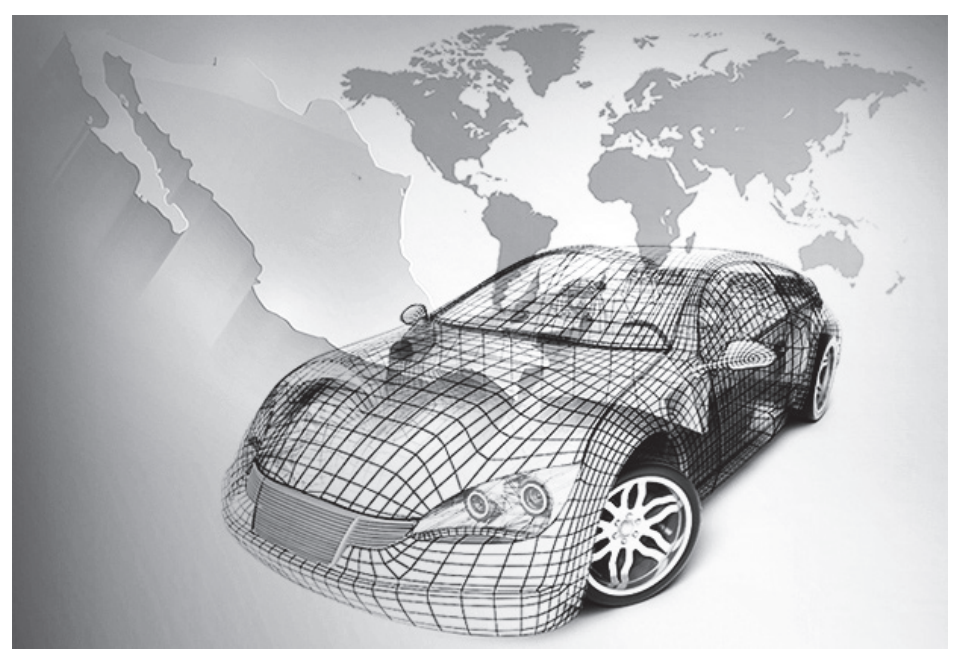

nes necesarias para llevar a cabo el plan de producción, se contemplan desde un principio las capacidades de los proveedores, incluyendo a sus propias redes, con quienes se han realizado ya las mencionadas alianzas; un sistema de trabajo que "deja escaso margen de decisión a las plantas armadoras establecidas en las distintas partes del mundo para contratar a proveedores locales" (Brown, 1997).

Sin embargo, la cantidad de partes necesarias para el automóvil de la tecnología y la estandarización de componentes (Brown, 1997) con una intensa cooperación entre ensambladora y proveeduría de primer nivel, surgiendo con ello alianzas estratégicas entre proveedores y ensambladoras, e incluso entre competidores.

Lo que ha ocurrido en México, ha sido que con la llegada de una planta ensambladora, llegan un conjunto de autopartistas con la capacidad de abastecer las demandas de la líder debido a, desde un principio, tres razones de gran importancia (Brown, 1997):

- Están dotadas de equipos técnicos capaces de diseñar las partes de los autos a partir de la tecnología más avanzada.

- Porque tienen la suficiente capacidad para abastecer grandes volúmenes de piezas a las distintas partes del mundo, sea exportándolas o montando plantas en los países donde se ubican las plantas terminales.

- Porque gran parte de las licitaciones para el abastecimiento a las plantas de las empresas terminales establecidas en diversos puntos geográficos se hacen en las casas matrices.

En otras palabras, en el diseño del producto, la decisión del lugar en donde se habrá de producir y cómo hacerlo, así como las inversioterminado es amplia, y existe, después de este gran proceso de decisiones, un conjunto de partes susceptibles de ser producidas por proveedores locales. Son entonces los proveedores de primer nivel, dada la estructura jerárquica de la red de proveeduría, una vez repartidas las partes de la producción con mayor contenido tecnológico, quienes generalmente integran a proveedores locales. Sin embargo, en este proceso de integración a la cadena, no cualquiera puede ser aceptado, pues la proveedora podría comprometer su producción y prestigio frente a sus clientes, poniendo en riesgo su propia participación en la cadena. Es sólo aquí en donde se abre una brecha de oportunidad para las PYMEs, sin embargo, éstas deben cumplir con ciertas condiciones.

De manera general, entre los requerimientos más importantes de las empresas de primer nivel a sus proveedores son: precio, calidad, volumen de entrega (Brown, 1997). Incluso, los proveedores "deben poseer una calificación de calidad mínima (ISO 9000, ISO 14000, QS9000, etc.) más una mayor (TS16949, Q1 mayor que 800, etc.), un volumen de ventas mínimo, un grado de especialización mínima y capacidades tecnológicas mínimas, entre otras cosas, simplemente para calificarse y postularse como proveedores" (Mortimore y Barrón, 2005). 
En algunos casos las proveedoras de primer nivel podrían optar por desarrollar a proveedores locales, sin embargo esto representa una inversión de la empresa, por lo que el temor a la no recuperación de la misma es un factor que lo impide, aunado a las características arriba mencionadas sobre las PYMEs en el país y su falta de capacidad para invertir, favorece a la falta de interés de las proveedoras de primer nivel.

Según Brown (1997) "para que las empresas puedan integrarse a la cadena de proveeduría en el segundo nivel, (...) se deben fortalecer la relaciones de cooperación entre los proveedores de primer y segundo nivel (...). Los proveedores de segundo nivel requieren apoyo de sus clientes en procesos de producción, en el diseño de las partes, el control de la calidad, y en los métodos para la reducción de costos. En segundo lugar, como señalan los empresarios del ramo, para aumentar la competitividad y productividad de éste grupo de empresas se precisan acciones gubernamentales tales como la promoción de proyectos ante bancos, universidades, proveedores de primer nivel, servicios de comunicación, servicios de logística, transporte y centros tecnológicos. (...). En suma, para aprovechar las oportunidades que existen en los vacíos de las cadenas productivas es necesario un esfuerzo conjunto de empresarios, gobierno y universidades".

Actualmente, existe cierto interés por desarrollar la proveeduría local "dada la ventaja de contar con proveedores locales (...) en distintos nichos como: inyección de plásticos, estampado, maquinado, troquelado, desarrollo de moldes, forja y fundición, empaque y embalaje, automatización, por mencionar algunos" (Meneses, 2015).

Sin embargo, en una encuesta realizada por la CEPAL (Mortimore y Barrón, 2005), según las propias empresas de la industria auto- motriz, principalmente las extranjeras, México "no cuenta con una suficiente y consolidada red de proveedores para avanzar más allá de una plataforma de exportación y convertirse en un centro de manufactura automotriz".

El problema principal, a pesar de la posibilidad de ingreso a la red de la proveeduría en la industria automotriz es a lo que llaman Mortimore y Barrón (2005) un "círculo vicioso", en donde por un lado a pesar de que existe el deseo de ampliar la base de proveedores locales, se tienen muy altas exigencias para el ingreso de éstos, debido a las características que debe tener el producto terminado, por lo que se les dificulta encontrar a los candidatos idóneos. Por el otro, los proveedores locales, en su mayoría, no disponen de las fortalezas necesarias para aprovechar las oportunidades que la red global ha abierto.

Localizando ésta debilidad, existen programas de apoyo impulsado por diversas instituciones como Bancomext, Nacional Financiera (Nafin), Instituciones estatales, organizaciones del sector público de otros países (JETRO, de Japón, por ejemplo), Instituciones del sector privado (ITESM), entre otras, que evidentemente a pesar de sus esfuerzos, éstos "no han sido suficientes para enfrentar al desafío de convertir la industria automotriz mexicana de una plataforma de exportación a un centro de manufactura" (Mortimore y Barrón, 2005), en donde exista una base de proveedores locales que se integren al proceso de producción, obteniendo como resultado, que sólo aquellos productos de menor valor agregado, en algunos casos, pues en gran medida son también importados, sean abastecidos por empresas nacionales, dejando la mayor parte del proceso a empresas extranjeras establecidas en el país, utilizando las ventajas que producir en México les otorga. Entre éstas ventajas podemos encontrar los costos relativos de la mano de obra; 
infraestructura de transporte acorde a los intereses de la empresa para llevar su producción a sus mercados destino; cercanía y fácil acceso a los mercados objetivo; una fuerza de trabajo capacitada; seguridad y certidumbre para las inversiones; instituciones de educación que provean de capacitación a los trabajadores; y un gobierno local que ofrece incentivos para que la localización de nuevas plantas se realice en el Estado, y la estrategia global de la compañía inversora.

Adicionalmente, es conveniente mencionar que la industria automotriz opera con un esquema de financiamiento basado en la proveeduría. Las grandes empresas adquieren la producción de sus proveedores y éstos últimos recibirán ganancias con un rezago de algunos meses. Sin embargo, ésta falta de obtención de beneficios de manera inmediata se compensa con contratos a medio y largo plazo, aunque es ésta una característica más que pesa sobre las débiles PYMEs que intentan buscar brechas de oportunidad en sectores rentables. Esto último resta rentabilidad al sector, lo que, aunado a las exigencias de la industria, constituyen un fuerte filtro a la entrada para las empresas que deseen ingresar.

\section{El TPP y la oportunidad prometida para las PYMES}

El Acuerdo Transpacífico de Cooperación Económica (Trans Pacific Partnership, тPP), tiene como finalidad anunciada el fomento el comercio entre los países miembros: Estados
Unidos, Australia, Brunei, Canadá, Chile, Japón, Malasia, México, Nueva Zelanda, Perú, Singapur y Vietnam. ${ }^{3}$

Se trata de un acuerdo de última generación ya que en sus apartados incluye temas como compras del sector público, derechos laborales, propiedad intelectual y de protección se trata de un ambiente.

Para la industria automotriz significaría acceso preferencial a un mayor número de mercados, lo que para algunos expertos podría traer como consecuencia una mayor insuficiencia en la infraestructura del país para satisfacer las demandas de la industria (carretera, férrea, portuaria, etc.).

El contenido regional del acuerdo, contempla que al revisar los componentes de un auto, las piezas deben promediar 45 por ciento del total de la manufactura. "La regla es similar al 62 por ciento que se pide en el TLCAN. Los porcentajes son similares porque el método de medición es distinto, en el tratado de libre comercio se pide una revisión de contenido

3 Las negociaciones de este tratado concluyeron en octubre de 2015, y se encontraba en revisión por los senados de los países firmantes para su ratificación. Sin embargo, en enero del 2017, el presidente de Estados Unidos, Donald Trump, firmó la orden ejecutiva para retirar a su país del acuerdo. El gobierno de Japón indicó que sin Estados Unidos como participante, el TPP no tenía sentido, por lo que algunos analistas consideran al TPP un tratado fallido. A pesar de ello, para otros más, es un acuerdo al que el gigante asiático, China, puede rescatar, cubriendo el vacío dejado por Estados Unidos quién lo había dejado fuera de las negociaciones del mismo como una estrategia comercial. 
regional con rastreo y en el TPP es por contenido neto", explicó Eduardo Solís, de la Asociación Mexicana de la Industria Automotriz (AMIA) en conferencia (Patiño y Sánchez, 2015).

En ese sentido, Arturo Rangel Bojórquez, Presidente de la Comisión de Comercio Exterior de la Cámara Nacional de la Industria de la Transformación (Canacintra), opina "Que nuestra frontera tenga una competencia implicará, en términos generales, que los sectores que en estos momentos son las joyas de la corona (como el automotor), se posicionen aún mejor", (Zúñiga, 2016).

Debido a lo anterior, en términos generales, con el TPP vienen mejores tiempos para la industria automotriz, pues incluso la AMIA (Asociación Mexicana de la Industria Automotriz) prevé que para 2020 se exporten cuatro millones de vehículos, cifra a la que se sumarian los efectos del тpp (Zúniga, 2016).

Sin embargo, ésta gran dinámica de la industria no necesariamente se verá reflejada en una mayor inclusión de las PYMEs mexicanas en la cadena de proveeduría, debido a que las características con las que cuentan no son las aptas para incluirse en dicha red.

Para que se logre una mayor integración, como Brown (1997) menciona, es necesaria la cooperación de empresas, gobierno y universidades, por lo que la ampliación del mercado por sí sola, no generará las condiciones necesarias para alcanzar dicha meta.

\section{Conclusiones}

La industria automotriz en México se caracteriza por ser un conjunto de empresas de origen extranjero, que se establecen en el país, donde destaca la participación de una empresa líder (la armadora), que con su llegada, trae la llegada de otras empresas más (autopartistas de primer nivel).
La producción del bien final en el lugar dado (el automóvil), corresponde a una estrategia global de producción en donde participan no solo la armadora, sino sus proveedoras de primer nivel con las que generan acuerdos de cooperación. Éstas últimas por lo general cuentan ya con sus propias proveedoras, por lo que la inclusión de empresas diferentes a la red, previamente establecida, es difícil.

Una vez llegado el conjunto de empresas con previa división y asignación de actividades, se abre la posibilidad de incluir proveedores locales. Sin embargo, dadas las características del producto final y las demandas de la líder, las exigencias de las proveedoras quienes generalmente son las que abren la posibilidad de inclusión a la red de participantes locales, son tan altas que no son capaces de ser alcanzadas por las empresas locales.

Éstas empresas, en nuestro caso las PYMEs, se enfrentan con dificultades de financiamiento, fuga de personal capacitado y problemas derivados de la falta de organización, falta de capacidad de pago de salarios competitivos, muy poca reinversión de utilidades para mejorar el equipo y las técnicas de producción, deficiencias en calidad debido a mínimos o inexistentes controles de la misma, entre otros.

Esto ha sido una característica general desde que el país se abrió al comercio internacional y trajo consigo el "éxito" de la industria automotriz "nacional".

A pesar de la existencia de diferentes instituciones que intentan dar apoyo a la inclusión de las PyMEs en la industria, sus esfuerzos han sido insuficientes.

Sin embargo, revisando un poco a profundidad los casos de "éxito" en donde ha sido posible la inclusión de empresas nacionales en la proveeduría automotriz, observamos que los principales insumos abastecidos por proveedo- 
res mexicanos y utilizados por los fabricantes de autopartes, se conforma por cuatro grandes rubros (Mortimore y Barrón, 2005,: 1) fundición, forja, estampados, maquinados y soldadura 2) lingotes y/o barras de aluminio y/o acero, 3) insumos indirectos, como aceites industriales, gases, electricidad y 4) hules, plásticos, fibras y vidrio (12\%); todos insumos que, dentro de la red de proveeduría global, contienen el más bajo contenido tecnológico, lo que implica a su vez que participan con un muy pequeńo valor del total del producto terminado, lo que determina un bajo nivel de ganancia dentro del total que la industria automotriz obtiene.

El TPP por su parte, implica una ampliación del mercado para la industria establecida en el país, lo que traerá consecuencias positivas (en términos de ventas, exportaciones, acceso a insumos especializados de menor costo, etc), si se superan los problemas de insuficiente infraestructura. Sin embargo, ello en definitiva no implica por sí solo una automática inclusión de las pymes en la red, por lo que es necesario un mayor esfuerzo por parte de las instituciones que ya operan y que no han tenido hasta hoy los mejores resultados.

Por todo lo anterior, tomando en consideración las características de la industria y las dificultades de la inclusión de las PyMEs, así como los esfuerzos hechos por las diversas instituciones públicas y privadas para el éxito de la mencionada inclusión en la red, así como sus resultados y casos de éxito, cabe plantear el siguiente cuestionamiento: ¿Vale la pena realizar dichos esfuerzos? ¿Vale la pena canalizar recursos a una industria que tiene una dinámica propia de toma de decisiones y deja los eslabones más bajos en donde los beneficios son los menores? ¿Vale la pena canalizar recursos a la inclusión de unas pyMEs en una red en donde no podrán crecer más allá del abastecimiento de insumos menores?
Se reconoce que los cuestionamientos son fuertes y en un esquema en donde uno es mejor que cero, todo esto funciona muy bien.

A manera de recomendación, es necesario el planteamiento de un esquema más amplio en donde no solo se intente la inclusión de las PYMES en una industria con una dinámica propia, que por su naturaleza relega los más bajos eslabones a la proveeduría local, sino el escalamiento en actividades de mayor valor agregado en donde la participación de empresas mexicanas sea más activa y representativa, dentro de un esquema todavía más amplio de desarrollo.

Se pretende con el presente artículo hacer una introducción al debate en torno al tema haciendo una pequeña contribución a la discusión.

\section{Bibliografía}

Álvarez Medina, María de Lourdes (2011), “Cadena de valor y organización productiva en la industria automotriz" en Isabel Rueda Peiro, María de Lourdes Álvarez Medina (coordinadoras) La industria automotriz en época de crisis. Efectos económicos, financieros y sociales, México. amia, Facultad de Contaduría y Administración, Instituto de Investigaciones Económicas.

Brown Grossman, Flor (1997) "La industria de Autopartes Mexicana Reestructuración reciente y perspectivas" División de Desarrollo Productivo y Empresarial de la cepaL, Centro Internacional de Investigaciones para el Desarrollo.

Cepal (2010), "La inversión extranjera en América Latina y el Caribe. Informe 2009”, Santiago de Chile, mayo. Publicación anualizada de las Naciones Unidas.

Dabat, Alejandro (2002), "Globalización, capitalismo actual y nueva configuración espacial del mundo", en Basave, Dabat, Morera, Rivera y Rodríguez (coords.), "Globalización y Alternativas Incluyentes para el Siglo XXI”, Amia, IIEc, 2002.

Dieter Ernst (2003), "Redes globales de producción, 


\section{Selene Jiménez Bautista y Carlos Mario Rodríguez Peralta |}

La inclusión de las PyMEs en la Cadena de valor de la

Industria Automotriz en México en el marco del TTP

difusión del conocimiento y formación de capacidades locales. Un marco conceptual”, en Enrique Dussel Peters (coords.), "La industria electrónica en México: problemática, perspectivas y propuestas", Universidad de Guadalajara, México

Eichner, Alfred (1988), "Microfundations of the Corporate Economy", en Toward a New Economics, Essays in Post-Keynesian and Institutionalist Theory, M. E. Sharpe, N.Y. Cap. 3, pp. 28-74.

García Gutiérrez, Patricia (1993), "El capitalismo de frontera en el norte de México. El caso de la Industria Automotriz", Universidad Autónoma Metropolitana, Primera edición, México D.F.

Juárez Núñez, Huberto, Lara Rivero, Arturo y Bueno, Carmen (Coords.) (2005), "El Auto Global. Desarrollo, competencia y cooperación en la industria del automóvil”, BUAP, UAM Xochimilco, Universidad Iberoamericana, Conacyt, Cd de México.

Instituto Nacional de Estadística y Geografía (INEGI), Banco de Información Económica: http://www. inegi.org.mx/sistemas/bie/

Kaplinsky, Raphael (2005), "Globalization, Poverty and Inequality”. Polity Press. London, England

López Arévalo, Jorge Alberto y Rodil Marazábal, Oscar (2008) "Comercio Intra-industrial e intra-firma en México en el contexto del proceso de integración de América del Norte (1993-2006)" en Revista Economía Amia, Vol. 5 Núm. 13, eneroabril, México, DF.

Meneses, Carlos (2015) "Industria Automotriz: En busca de las pymes mexicanas", Fumec Empresarial, Recuperado de: http://www.fumec.org/ empresarial/?p=917

Mortimore, Michael y Barrón, Faustino (2005) "Informe sobre la industria automotriz mexicana” Serie desarrollo productivo, cepal, Santiago de Chile.

Organisation Internationale des Constructeurs d'Automobiles (OICA): http://www.oica.net/category/about-us/

Patiño, Dainzú y Sánchez, Axel (04.11.2015) "Manufacturas se abren con el TPP... con exclusiones en sector automotriz" Periódico El Financiero, $\mathrm{Pu}$ - blicación en Linea: http://www.elfinanciero.com. $\mathrm{mx} / \mathrm{economia/ttp-detonaria-industria-automotriz.}$ html

Pérez, Carlota (2004), "Revoluciones tecnológicas y capital financiero. La dinámica de las grandes burbujas financieras y las épocas de bonanz a ". Siglo XXI Editores, México

Pérez, Carlota. (1992) "Cambio técnico, reestructuración competitiva y reforma institucional en los países en desarrollo", en: El Trimestre Económico, vol. LIX (1), enero-marzo, núm. 233

Penrose, Edith (1959) "The Theory of the growth of the firm”, Oxford University Press, 1995.

Proméxico (2016) "PYMes, eslabón fundamental para el crecimiento en México" (online) Disponible en: http://www.promexico.gob.mx/negocios-internacionales/pymes-eslabon-fundamental-parael-crecimiento-en-mexico.html (revisado el 14 de Diciembre del 2016)

Rodríguez Peralta, Carlos (2013) "Oligopolio y competencia mundial en la industria automotriz. La emergencia del Toyotismo y la caída del Fordismo", en Economía Informa, Noviembre-Diciembre, Número 383, México D.F.

Romero, Indira (2011), "Impacto asimétrico de la crisis global sobre la industria automotriz: Canadá y México comparados. Perspectivas para el futuro", Estudios y Perspectivas, publicación de las Naciones Unidas, Cepal, México DF.

Secretaría de Economía (2012) "Industria Automotriz. Monografía” Dirección General de Industrias Pesadas y de Alta Tecnología. Publicación en Línea : http://www.economia.gob.mx/files/comunidad_ negocios/industria_comercio/Monografia_Industria_Automotriz_MARZO_2012.pdf

Sylos Labini, P. (1966), "Oligopolio y progreso técnico", Ediciones oikos-tau, Barcelona, España.

Zúńiga, Erick (05.02.2016) "Oportunidades del трг para la industria automotriz” Revista Transportes y Turismo, Publicación en Línea: http://tyt.com. $\mathrm{mx} /$ noticias/oportunidades-del-tpp-para-la-industria-automotriz/ 
Estimado(a) colaborador(a):

A continuación presentamos los criterios técnicos para la presentación de artículos de la revista Economía Informa.

\section{Requerimientos del texto:}

- Una página principal que incluya: título del artículo, nombre completo del autor, resumen académico y profesional, líneas de investigación, dirección, teléfono y correo electrónico.

- Un resumen del artículo de máximo 10 líneas.

- Incluir la clasificación (JEL) y tres palabras clave.

- Usar notas al pie de página ocasionalmente y sólo si son indispensables.

- Citas y referencias en el texto deben cumplir con los requisitos del sistema de referencias Harvard.

- Explicar por lo menos una vez los acrónimos y/o abreviaturas usadas en el texto.

- La bibliografía final debe también cumplir los criterios del sistema de referencia Harvard. La lista de referencias debe corresponder con las citas del documento.

\section{Extensión y características técnicas:}

- Ningún artículo puede exceder 30 páginas; incluyendo todas las secciones del manuscrito.

- Debe estar en Word.

- La letra debe ser Times New Roman, tamaño 12.

- El formato es tamańo carta (A4).

- No se usa sangrías (ni en el texto ni en las referencias bibliográficas)

- El uso de itálicas está reservado para el título de libros, journals, nombres científicos y letras que no estén en castellano.

- El uso de comillas está reservado para el título de: artículos, capítulos de libros y citas incluidas en el texto.

Tablas, gráficos y otros materiales de apoyo:

- Preferiblemente en Excel. De lo contrario usar: jpeg, tiff, png o gif.

- Se deben proporcionar los archivos originales en un sólo documento.

- Incluir los materiales también en el texto.

- Deben ser auto contenidos. Es decir, no se necesita del texto para ser explicados. No incluir abreviaciones. Indicar de manera clara las unidades de medida así como citas completas.

- Deben encontrarse en blanco y negro.

- Las tablas deben ser simples y relevantes.

- Los títulos, notas y fuentes del material deben ser capturados como parte del texto del documento. No deben ser insertados en el cuerpo del gráfico, figura y/o tabla.

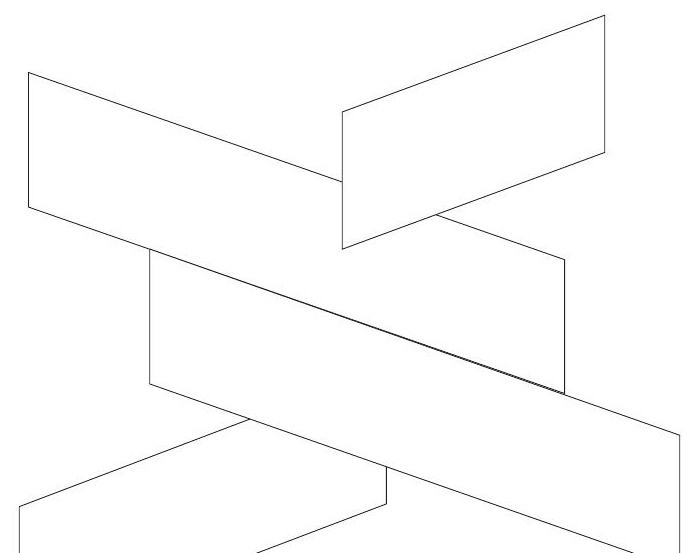

